\title{
Fruit and vegetable intake in Austrian adults: intake frequency, serving sizes, reasons for and barriers to consumption, and potential for increasing consumption
}

\author{
Manuel Schätzer ${ }^{1,2}$, Petra Rust ${ }^{1, *}$ and Ibrahim Elmadfa ${ }^{1}$ \\ 'Department of Nutritional Sciences, University of Vienna, Althanstrasse 14, 1090 Vienna, Austria: \\ ${ }^{2}$ Special Institute for Preventive Cardiology and Nutrition, Salzburg, Austria
}

Submitted 1 August 2008: Accepted 29 July 2009: First published online 7 0ctober 2009

\begin{abstract}
Objective: To assess the intake frequency of fruit and vegetables, serving sizes, reasons for and barriers to consumption, and the potential for increasing fruit and vegetable intake.

Design: A nationwide postal questionnaire survey was conducted in 2006 over all four seasons. The participants were stratified according to occupation and sex. The response rate for 5130 questionnaires sent out was $52 \cdot 7 \%$.

Setting: Austria.

Subjects: Austrian adults, aged 19-64 years.

Results: Daily fruit consumption was reported by $57 \cdot 1 \%$ of the participants and daily vegetable consumption by $36 \cdot 2 \%$. On average, $2 \cdot 1$ (SD 1.9) servings (250 (SD 225) g) of fruit and $1 \cdot 7$ (SD 1.3) servings (198 (SD 159) g) of vegetables were consumed daily. Women ate fruit and vegetables both more frequently and in greater quantities than men. Both intake frequency and the number of fruit and vegetable servings were largely independent of seasonal fluctuations. The primary reason for the consumption of both fruit and vegetables was taste. The greatest barrier to higher intake was the perception that current individual consumption was already sufficient. Price did not constitute a relevant barrier in Austria. At present, the potential for increasing fruit and vegetable intake can be estimated at two servings.

Conclusions: Austrian adults still consume less fruit and vegetables than recommended. Strategies to increase intake should pay more attention to the taste instead of the various health aspects.
\end{abstract}

Keywords
Fruit
Vegetables
Consumption
Barriers
Potential for increasing consumption

Obesity, type 2 diabetes mellitus, CVD (e.g. hypertension, stroke) and several types of cancer are becoming increasingly important causes of early mortality or permanent morbidity ${ }^{(1)}$. The influence and importance of a varied and wholesome diet on health and thus also on the prevention of chronic diseases is now widely accepted ${ }^{(2)}$. Epidemiological studies have indicated that fruit and vegetable intake has a major influence on cancer risk ${ }^{(3)}$. Contrary to initial results from case-control studies, however, results from cohort studies show that while an effect is possible, it is restricted to certain types of cancer $^{(4,5)}$. Both fruit and vegetables probably reduce the likelihood of developing mouth, laryngeal, oesophageal and stomach cancer ${ }^{(6)}$. Concerning the relative risk of developing cancer, it was shown that even an increment of five servings of fruit and vegetables per day apparently does not decrease the risk $^{(7,8)}$. In contrast, the positive effects of sufficient fruit and vegetable consumption on the cardiovascular system are now largely validated ${ }^{(9,10)}$. Meta-analyses also showed that increased fruit and

vegetable intake is associated with a reduced risk of stroke $^{(11,12)}$. However, the intake of three or more daily servings of fruit or vegetables was not associated with a substantial reduction in the risk of type 2 diabetes according to meta-analysis ${ }^{(13)}$. The effect of fruit and vegetable intake on body weight should not be underrated. As people tend to consume similar weights of food every day, total energy intake decreases with decreasing energy content of the foodstuffs. In this context, a positive effect of sufficient fruit and vegetable intake has been demonstrated $^{(14)}$.

The most important initiative worldwide to increase vegetable and fruit consumption is ' 5 a day'. In Austria, the campaign ' 5 a day - fruit and vegetables' was presented to the public by the Austrian Cancer League (in cooperation with the Institute of Nutritional Sciences of the University of Vienna) in autumn 2000 and has been widely advertised since 2001. ' 5 a day' is a rather important message to increase intake ${ }^{(15)}$, especially as different individual barriers prohibit a higher consumption. 
Reasons, besides $\operatorname{cost}^{(16)}$, could be availability ${ }^{(17)}$, impractical if not at home ${ }^{(18)}$ or preparation effort ${ }^{(19)}$.

The present paper describes fruit and vegetable intake in Austrian adults, barriers to increased intake, and the current potential for increasing consumption.

\section{Methods}

The study design was cross-sectional. Four independent sub-samples (one for each season) of a total of 5130 adults (aged 19-64 years) from throughout Austria were surveyed over the course of one year in 2006, in order to measure seasonal fluctuations. The sample was stratified by sex and occupation. Occupation was chosen as a criterion because it gives information on further sociodemographic characteristics $^{(20)}$. Sample size was calculated based on the occupational distribution. We excluded people older than 65 years from the analysis. In order to access the chosen occupational groups effectively, companies, public and private institutions were chosen randomly. Following initial contact by telephone, which served to acquire a competent contact person, an appropriate number of questionnaires according to the stratification sampling design were mailed to each contact. It was attempted to keep the selection bias as low as possible with this method. The response rate was $52 \cdot 7 \%$ (2704 adults). Representativeness of the data regarding current employment status, age structure, sex, the highest level of education and household income was verified using data provided by Statistik Austria. The characteristics of the study sample are shown in Table 1.

\section{Questionnaire design}

A self-administered questionnaire with questions on different topics regarding fruit and vegetables was used. The complete questionnaire contained thirty-nine closed questions. Questions on reasons for consumption ('because it tastes good', 'because it is healthy', 'because it is available') and barriers for consumption ('intake is already sufficient', 'I often forget to eat fruit/vegetables', 'I often don't feel like it', 'too much preparation effort', 'inconvenient if not at home', 'too expensive', 'does not suit my lifestyle', 'function of higher consumption is unknown') were dichotomous questions but allowed multiple answers. FFQ were used for a qualitative assessment ('How often do you eat...') of the intake of different types of fruit and vegetables. A single self-administered $24 \mathrm{~h}$ recall survey was used to obtain quantitative information $(\mathrm{g} / \mathrm{d})$ on fruit and vegetable intake ${ }^{(21)}$. The intake was measured by household measures. The questionnaire was developed during two pre-test phases and its reliability was evaluated by the test-retest method. For eighty-five out of eighty-six ordinal questions, the test-retest reliability was rated 'good' or 'very good' (intra-class correlation $>0 \cdot 6$ ). Only for one parameter was the test-retest reliability 'acceptable' (intra-class correlation $>0 \cdot 50$ to $0 \cdot 59$ ). For sixty-two out of seventy-five dichotomous
Table 1 Major characteristics of the study sample according to season: Austrian adults participating in a nationwide postal questionnaire survey, 2006

\begin{tabular}{|c|c|c|c|c|c|}
\hline Characteristic & Total & Spring & Summer & Autumn & Winter \\
\hline$n$ & 2704 & 620 & 672 & 643 & 769 \\
\hline Response rate (\%) & $52 \cdot 7$ & $44 \cdot 6$ & $54 \cdot 0$ & $51 \cdot 7$ & $60 \cdot 7$ \\
\hline \multicolumn{6}{|l|}{ Age (years) } \\
\hline Mean & 38 & 38 & 38 & 38 & 39 \\
\hline SD & 11 & 11 & 11 & 11 & 11 \\
\hline \multicolumn{6}{|l|}{ Age distribution (\%) } \\
\hline $19-24$ years & $13 \cdot 8$ & $12 \cdot 0$ & $12 \cdot 5$ & $17 \cdot 6$ & $13 \cdot 1$ \\
\hline $25-50$ years & $70 \cdot 6$ & $73 \cdot 2$ & $72 \cdot 6$ & $67 \cdot 3$ & $69 \cdot 6$ \\
\hline $51-64$ years & $15 \cdot 6$ & $14 \cdot \overline{9}$ & $14 \cdot 9$ & $15 \cdot 1$ & $17 \cdot 3$ \\
\hline \multicolumn{6}{|l|}{ Sex $(\%)$} \\
\hline Male & $39 \cdot 9$ & $41 \cdot 0$ & $42 \cdot 1$ & $36 \cdot 2$ & $40 \cdot 2$ \\
\hline Female & $60 \cdot 1$ & $59 \cdot 0$ & $57 \cdot 9$ & $63 \cdot 8$ & $59 \cdot 8$ \\
\hline \multicolumn{6}{|l|}{ Occupation (\%) } \\
\hline Labourer & $14 \cdot 1$ & $10 \cdot 5$ & $12 \cdot 0$ & $16 \cdot 0$ & $17 \cdot 3$ \\
\hline Employee & $23 \cdot 7$ & $31 \cdot 1$ & $23 \cdot 1$ & $21 \cdot 9$ & $19 \cdot 7$ \\
\hline Self-employed & $5 \cdot 1$ & $5 \cdot 2$ & $5 \cdot 2$ & $4 \cdot 3$ & $5 \cdot 4$ \\
\hline Unemployed & $4 \cdot 4$ & $2 \cdot 2$ & $6 \cdot 0$ & $5 \cdot 5$ & $3 \cdot 9$ \\
\hline Housewife & $6 \cdot 6$ & $3 \cdot 8$ & $7 \cdot 7$ & $6 \cdot 0$ & $8 \cdot 3$ \\
\hline Student & $3 \cdot 1$ & $4 \cdot 2$ & $2 \cdot 9$ & $3 \cdot 2$ & $2 \cdot 5$ \\
\hline \multicolumn{6}{|l|}{ Region (\%) } \\
\hline East & $42 \cdot 2$ & $31 \cdot 6$ & $47 \cdot 3$ & $41 \cdot 1$ & $47 \cdot 1$ \\
\hline West & $57 \cdot 8$ & $68 \cdot 4$ & $52 \cdot 7$ & $58 \cdot 9$ & $52 \cdot 9$ \\
\hline
\end{tabular}

variables, concordance was over $80 \%$; for thirteen variables, concordance was between $71 \%$ and $80 \%$.

\section{Analysis}

The SPSS for Windows statistical software package version $12 \cdot 0$ (SPSS Inc., Chicago, IL, USA) was used to analyse the data. All questions were analysed with respect to sex, age, season and geographical region. Data for fruit and vegetable intake were 'raw data' and were not adjusted for energy. We used the $\chi^{2}$ test (standard residuals were used to determine significant differences) for dichotomous data and the Mann-Whitney $U$ test for ordinal data. $P$ values were adjusted for multiplicity according to the Bonferroni-Holm procedure.

The data from the $24 \mathrm{~h}$ recalls were entered into the 'Ernährungswissenschaftliche Programm'. This software is based on the German Food Database Version II.3 but was adapted for Austrian eating habits through the addition of typical Austrian recipes ${ }^{(22)}$.

To adjust for under-reporting as well as for over-reporting, the quotient of the recorded energy intake and the individually calculated BMR, after Schofield, was used ${ }^{(23)}$. Based on cut-off points, participants with an extremely high or extremely low energy intake could subsequently be identified ${ }^{(24-26)}$. The cut-off points used were $2 \cdot 4$ for over-reporting and 0.92 for under-reporting ${ }^{(27)}$.

\section{Results}

\section{Consumption of fruit}

The qualitative assessment showed that the intake frequency of fruits in Austria is too low. According to their 
own accounts, $22 \cdot 7 \%$ of the respondents consumed fruit several times a day, $34 \cdot 4 \%$ once a day, $11 \cdot 7 \%$ ate fruit four to six times per week and $21.9 \%$ between one and three times per week. Some $10 \cdot 3 \%$ of the participants consumed fruit only every second week or less often.

Women reported a significantly higher $(P<0 \cdot 001)$ intake frequency of fruit than men, with $65.6 \%$ of participating women reporting consumption of fruit at least once a day compared with $44 \cdot 2 \%$ of men. Thus, women consumed fruit on average once a day, men only four to six times a week.

A significant increase in intake frequency was found with increasing age (19-24-year-olds $v$. 25-50-year-olds, $P<0 \cdot 001$; 19-24-year-olds $v$. 51-64-year-olds, $P<0 \cdot 001$; 25-50-year-olds $v$. 51-64-year-olds, $P<0 \cdot 001$ ). While women over 25 years old consumed fruit significantly more frequently than younger women, in men the same applied only to participants aged 51 years and over. No significant difference in the intake frequency of fruit was found between eastern and western Austria or between seasons.

According to the data from the $24 \mathrm{~h}$ recalls, the participants ate on average 250 (SD 225) g of fruit (not including fruit juices) per day. This is a greater amount than described in the second Austrian nutrition report $2003(183(\mathrm{sD} 227) \mathrm{g} / \mathrm{d})^{(28)}$. Assuming a serving size of $120 \mathrm{~g}$ (according to the recommendation of $600 \mathrm{~g}$ per person per day to reach public health goals) ${ }^{(29)}$, the participants consumed on average $2 \cdot 1$ (SD 1.9) servings of fruit per day.

The proportion of people consuming less than one serving of fruit per day was $29 \cdot 0 \%, 26 \cdot 6 \%$ consumed one serving a day and nearly half of the respondents (44.5\%) estimated their consumption as two servings of fruit per day.

On average, men ate $2 \cdot 0$ (SD $2 \cdot 0)$ servings (237 (SD 262) g) and women ate $2 \cdot 1(\mathrm{SD} 1 \cdot 7)$ servings (256 (SD 206) g) of fruit per day. Still, $47 \cdot 4 \%$ of the women reached the recommended daily amount of two servings of fruit per day, whereas only $38.3 \%$ of men did.

Regarding age, it was shown that only $29 \cdot 6 \%$ of 19-24year-olds, $44.9 \%$ of $25-50$-year-olds and $53 \cdot 0 \%$ of $51-64$ year-olds met the recommended two daily fruit servings.

According to overall intake frequency, there were no significant differences in average serving sizes between eastern and western Austria and between the different seasons.

\section{Consumption of vegetables}

Vegetables were consumed less frequently than fruit: $7 \cdot 7 \%$ of the respondents reported consuming vegetables several times a day, $28.5 \%$ ate vegetables once a day, $22 \cdot 2 \%$ ate vegetables four to six times per week and $34 \cdot 2 \%$ one to three times per week. Some $7 \cdot 3 \%$ of all participants reported consuming vegetables only every second week or less frequently.

Women reported a significantly $(P<0 \cdot 001)$ higher intake frequency of vegetables than men. Of female participants, $42 \cdot 0 \%$ indicated that they ate vegetables at least once a day, compared with $27 \cdot 5 \%$ of participating men. For both women and men, the average intake frequency was four to six times a week.

Regarding the effect of age, the results showed that women aged 19-24 years ate vegetables significantly $(P=0 \cdot 03)$ less frequently than women aged $25-50$ years. In men, intake frequency was approximately the same for all ages. People from western Austria consumed vegetables significantly $(P<0 \cdot 001)$ more frequently than participants from the east of the country.

Concerning intake frequency during the different seasons, the data showed that the participants consumed vegetables significantly $(P<0 \cdot 001)$ less frequently in winter than in the summer season.

According to the data from the $24 \mathrm{~h}$ recalls, the participants ate on average 198 (SD 159) g of vegetables per day. As found for fruit, this amount is greater than that published in the second Austrian nutrition report $2003(148(\mathrm{sD} \mathrm{134}) \mathrm{g} / \mathrm{d})^{(28)}$. Assuming a serving size of $120 \mathrm{~g}$, the participants ate on average $1 \cdot 7$ (SD $1 \cdot 3$ ) servings of vegetables per day.

Of the participants, $37 \cdot 2 \%$ consumed less than one serving per day, almost one-third (31.0\%) consumed one serving per day and nearly one-sixth $(17 \cdot 1 \%)$ consumed two servings of vegetables per day. The recommendation of eating three servings of vegetables daily was met by only $14.7 \%$ of the respondents.

Men ate significantly $(P<0 \cdot 001)$ fewer servings of vegetables than women. On average, men ate $1.5(\mathrm{SD} 1 \cdot 2)$ servings (180 (SD 149) g) and women ate 1.7 (SD 1.4) servings (208 (SD 164) g) of vegetables per day. Only $11 \cdot 2 \%$ of men and $16 \cdot 6 \%$ of women met the recommendation to consume three servings of vegetables per day. Regarding age, it was shown that only $9 \cdot 1 \%$ of 19-24-year-olds, $15 \cdot 6 \%$ of 25-50-year-olds and $15 \cdot 6 \%$ of 51-64-year-olds consumed the recommended three daily servings. Again, there was no significant difference between western and eastern Austria or between the seasons.

\section{Reasons for consumption}

Regarding reasons for the consumption of fruit and vegetables, the respondents could choose between three response options ('because it tastes good', 'because it is healthy' and 'because it is available').

The results showed that taste was the most important factor for the intake of both fruit and vegetables (Tables 2 and 3). In addition to the health aspect, availability also played an important role. This was especially the case for men in general and for the age group 19-24 years.

With increasing intake frequency, it was found that taste and the health aspect became more important motives for the intake of both fruit and vegetables, whereas the importance of availability decreased. 
Table 2 Motives for the intake of fruit according to sex, age and intake frequency: Austrian adults participating in a nationwide postal questionnaire survey, 2006

\begin{tabular}{|c|c|c|c|c|c|c|c|c|c|c|c|}
\hline \multirow[b]{2}{*}{ Motive } & \multirow[b]{2}{*}{$\begin{array}{c}\text { Total } \\
(n 2681)\end{array}$} & \multicolumn{2}{|c|}{ Sex } & \multicolumn{3}{|c|}{ Age - total } & \multicolumn{5}{|c|}{ Intake frequency } \\
\hline & & $\begin{array}{c}\text { Men } \\
(n \text { 1067) }\end{array}$ & $\begin{array}{l}\text { Women } \\
(n \text { 1614) }\end{array}$ & $\begin{array}{c}19-24 \text { years } \\
(n 366)\end{array}$ & $\begin{array}{c}25-50 \text { years } \\
(n 1897)\end{array}$ & $\begin{array}{c}\text { 51-64 years } \\
(n 418)\end{array}$ & $\begin{array}{l}\text { Several times/d } \\
\quad(n 610)\end{array}$ & $\begin{array}{c}1 \times / d \\
(n 928)\end{array}$ & $\begin{array}{c}6-4 \times / \text { week } \\
(n 315)\end{array}$ & $\begin{array}{c}3-1 \times / \text { week } \\
(n 567)\end{array}$ & $\begin{array}{c}<1 \times / \text { week } \\
(n 252)\end{array}$ \\
\hline Because it tastes good (\%) & $78 \cdot 3$ & $72 \cdot 1$ & $82 \cdot 5$ & $75 \cdot 4$ & $78 \cdot 7$ & $79 \cdot 2$ & $93 \cdot 8$ & $84 \cdot 4$ & $85 \cdot 4$ & $64 \cdot 9$ & $40 \cdot 9$ \\
\hline Because it is healthy $(\%)$ & $47 \cdot 6$ & $43 \cdot 6$ & $50 \cdot 2$ & $45 \cdot 1$ & $47 \cdot 1$ & $52 \cdot 2$ & $60 \cdot 8$ & $53 \cdot 7$ & $53 \cdot 7$ & $33 \cdot 7$ & $23 \cdot 6$ \\
\hline Because it is available (\%) & $30 \cdot 2$ & $34 \cdot 9$ & $27 \cdot 2$ & $39 \cdot 9$ & $29 \cdot 9$ & $23 \cdot 4$ & $17 \cdot 5$ & $19 \cdot 7$ & $19 \cdot 7$ & $45 \cdot 1$ & $64 \cdot 9$ \\
\hline
\end{tabular}

Table 3 Motives for the intake of vegetables according to sex, age and intake frequency: Austrian adults participating in a nationwide postal questionnaire survey, 2006

\begin{tabular}{|c|c|c|c|c|c|c|c|c|c|c|c|}
\hline \multirow[b]{2}{*}{ Motive } & \multirow[b]{2}{*}{$\begin{array}{c}\text { Total } \\
(n \text { 2679) }\end{array}$} & \multicolumn{2}{|c|}{ Sex } & \multicolumn{3}{|c|}{ Age - total } & \multicolumn{5}{|c|}{ Intake frequency } \\
\hline & & $\begin{array}{c}\text { Men } \\
(n \text { 1070) }\end{array}$ & $\begin{array}{l}\text { Women } \\
(n \text { 1609) }\end{array}$ & $\begin{array}{l}\text { 19-24 years } \\
(n 365)\end{array}$ & $\begin{array}{c}25-50 \text { years } \\
(n 1896)\end{array}$ & $\begin{array}{l}\text { 51-64 years } \\
(n 418)\end{array}$ & $\begin{array}{c}\text { Several times/d } \\
(n 207)\end{array}$ & $\begin{array}{l}1 \times / d \\
(n 767)\end{array}$ & $\begin{array}{c}6-4 \times / \text { week } \\
(n 598)\end{array}$ & $\begin{array}{c}3-1 \times / \text { week } \\
(n 920)\end{array}$ & $\begin{array}{c}<1 \times / \text { week } \\
(n 189)\end{array}$ \\
\hline Because it tastes good (\%) & $77 \cdot 4$ & $67 \cdot 4$ & $84 \cdot 1$ & $75 \cdot 6$ & $79 \cdot 0$ & $71 \cdot 8$ & $94 \cdot 2$ & $87 \cdot 2$ & $81 \cdot 1$ & $70 \cdot 0$ & $42 \cdot 6$ \\
\hline Because it is healthy (\%) & $49 \cdot 6$ & $44 \cdot 0$ & $53 \cdot 3$ & $44 \cdot 1$ & $49 \cdot 9$ & $52 \cdot 9$ & $63 \cdot 8$ & $56 \cdot 1$ & $48 \cdot 8$ & $45 \cdot 7$ & $29 \cdot 0$ \\
\hline Because it is available (\%) & $37 \cdot 6$ & $42 \cdot 9$ & $34 \cdot 1$ & $43 \cdot 3$ & $35 \cdot 3$ & $42 \cdot 8$ & $32 \cdot 9$ & $30 \cdot 5$ & $37 \cdot 1$ & $40 \cdot 9$ & $57 \cdot 9$ \\
\hline
\end{tabular}




\section{Barriers to consumption}

To evaluate consumption barriers, eight relevant response options were provided that were based on internal and external barriers according to John and Zeibland $^{(18)}$. The five most important barriers to consumption of fruit or vegetables were: 'intake is already sufficient', 'I often forget to eat fruit/vegetables', 'I often don't feel like it', 'too much preparation effort', and 'inconvenient if not at home'. In contrast to other stu$\operatorname{dies}^{(16,30-33)}$, price constituted only a minor barrier to a higher intake of fruit or vegetables. In addition to price, the association between fruit and vegetable intake and one's lifestyle ('does not suit my lifestyle') and lack of knowledge why a higher consumption is better ('function of higher consumption is unknown') were not barriers for a higher intake in Austria.

Additionally, the eight consumption barriers were considered in relation to intake groups (fruit intake: 'less than one serving per day', 'one serving per day', 'two or more servings per day'; vegetable intake: 'less than one serving per day', 'one to two servings per day', 'three or more servings per day'; Tables 4 and 5).

The percentage of people stating that their intake was sufficient increased with increasing intake of both fruit and vegetables. There is some reason for concern given that, in the groups consuming less than one serving of fruit or vegetables per day, respectively $31 \cdot 3 \%$ and $54.0 \%$ nevertheless considered their intake sufficient. This response was given especially often by people over 50 years of age. Regarding fruit intake, the results showed that in the group consuming less than one serving per day, a lack of liking was particularly prevalent (33.8\%). Moreover, $50.4 \%$ in this intake group simply forget to consume fruit.

While preparation effort played only a minor role in hindering consumption of fruit, it posed a significant barrier to consumption of vegetables in all three intake groups (less than one serving per day: $23 \cdot 0 \%$, one to two servings per day: $21.4 \%$, three or more servings per day: $19 \cdot 4 \%$ ).

\section{Increasing consumption}

Regarding intake of fruit, $20 \cdot 8 \%$ of the participants indicated they did not want to increase their intake. Over half of the respondents $(55.0 \%)$ could imagine increasing consumption by one serving per day, 20.3\% felt they would be able to increase intake by two servings and $3.9 \%$ by three or more servings per day. No differences were found between men and women or between the different age groups. On average, the increase potential is one serving of fruit per day.

Concerning intake of vegetables, $40 \cdot 1 \%$ of the participants indicated they did not wish to increase their intake. Half of the respondents $(50 \cdot 1 \%)$ could imagine eating an additional serving of vegetables per day. Only $8 \cdot 2 \%$ of the participants would be willing to eat two more servings per day and merely $1.5 \%$ would increase their intake by

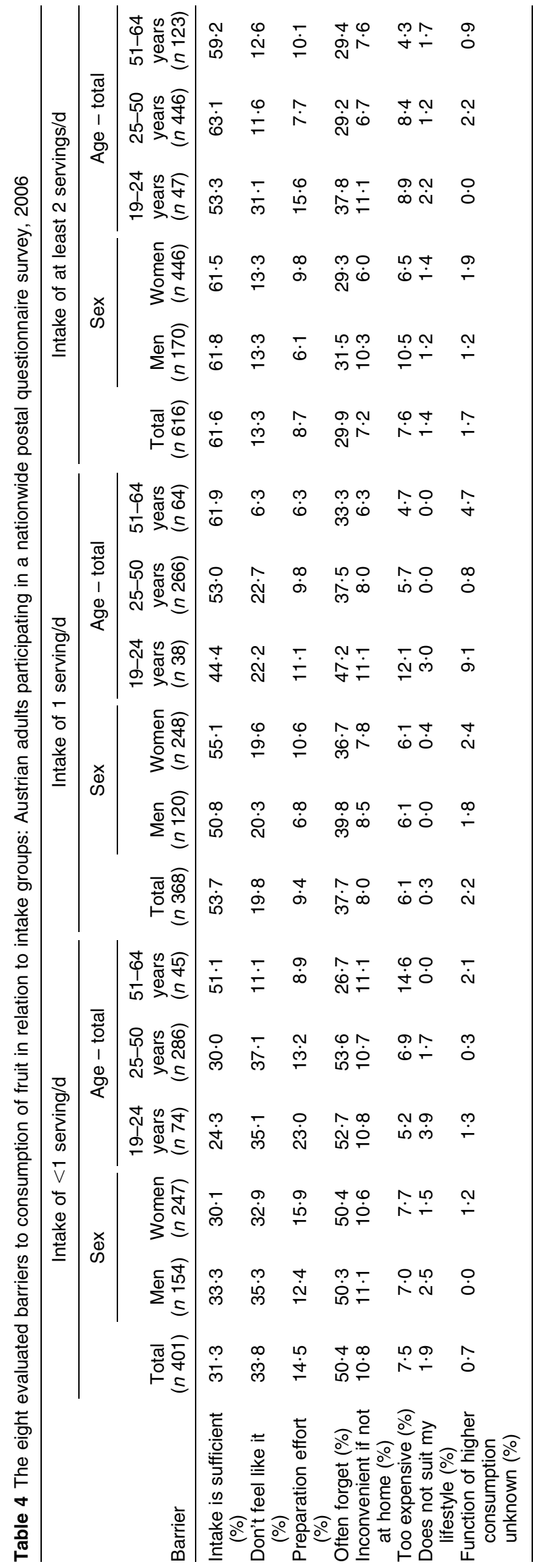




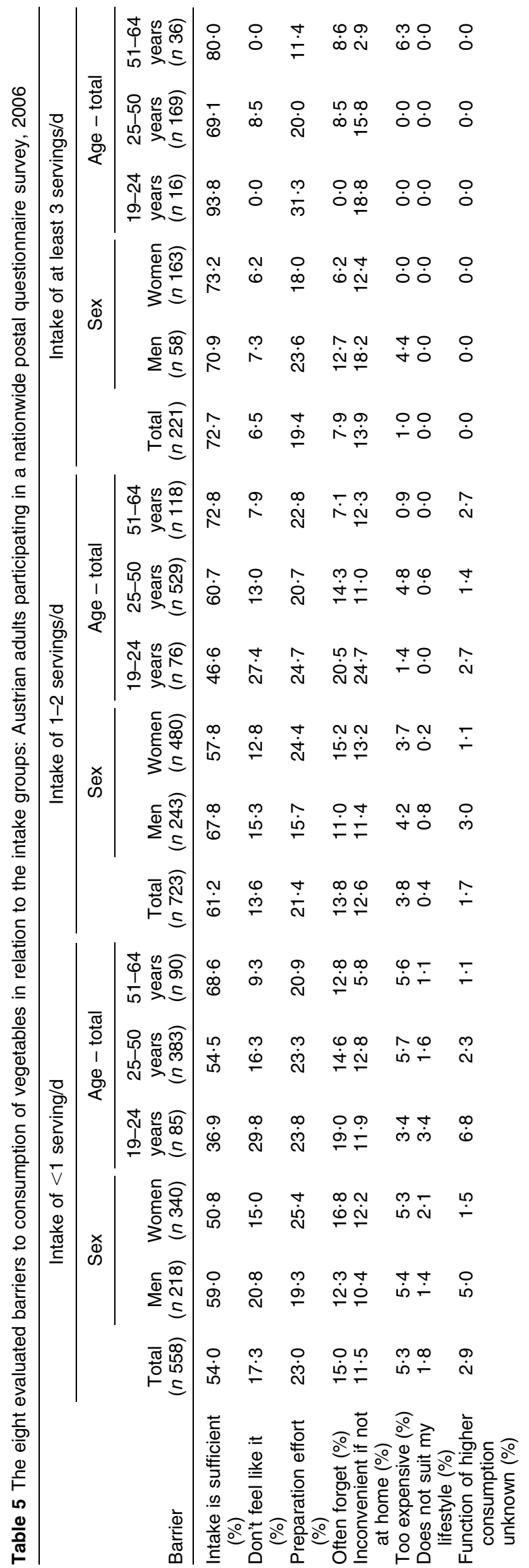

three or more servings. While the different age groups did not differ significantly in their willingness to increase intake, there was a significant difference between men and women $(P<0 \cdot 001): 43.6 \%$ of male respondents could not presently imagine consuming one or more additional servings of vegetables per day; for women, this figure was $37 \cdot 8 \%$. The average increase potential is one serving of vegetables per day.

At present, the average potential for increasing fruit and vegetable consumption can be estimated at one serving for fruit as well as vegetables per day. Thus, on average, daily serving amounts could be increased to 5.9 (SD 1.7) servings in women and to $5.6(\mathrm{SD} 1 \cdot 7)$ servings in men.

\section{Discussion}

The chosen study design facilitated a very efficient implementation and a high response rate. Due to representativeness of the data the results are representative for the adult Austrian population. The major selection bias we had to deal with was the well-known fact that women are more-health conscious and therefore are more interested in nutritional surveys. The $24 \mathrm{~h}$ recall was, as expected, the greatest source for bias. It would have been better to instruct participants on portion sizes by using picture examples to further increase the quality of data.

The results clearly show that Austrian adults consume insufficient amounts of fruit and vegetables evaluated by FFQ and $24 \mathrm{~h}$ recall. Despite the low intake, it is notable that fruit intake has increased by $67 \mathrm{~g} / \mathrm{d}$ and vegetable intake by $50 \mathrm{~g} / \mathrm{d}$ since $2003^{(28)}$. Still, the consumption frequency is an important reason for the insufficient intake: $43.0 \%$ of all respondents do not consume fruit daily and $63.7 \%$ do not consume vegetables daily. The fact that women eat more servings of fruit and vegetables than men reflects typical sex-specific differences in health behaviour in uustria $^{(34)}$. Given that availability of fruit and vegetables plays an important role in consumption behaviour particularly of men, as reported in various studies $^{(35-37)}$, attempts to increase intake should address this issue more. It can be speculated whether it would be a suitable strategy, besides promoting employee health schemes, to encourage women in their role as spouses and partners to facilitate availability of fruit and vegetables to men, as the results of the questionnaire showed that women are significantly $(P<0 \cdot 001)$ more often responsible for grocery shopping.

Regarding vegetable intake, the results reflect the wellknown west-east gradient in health-conscious nutrition ${ }^{(38)}$. One major reason for this could be the relationship between nutrition and lifestyle factors such as physical activity and smoking behaviour ${ }^{(39-42)}$. People in eastern Austria not only eat less vegetables but also smoke significantly $(P<0 \cdot 001)$ more and get significantly ( $P=0 \cdot 001)$ less exercise than people in the west. 
The constant level of intake of fruit over the course of the year can be regarded as very positive. One reason for the difference in vegetable intake between the winter and summer seasons could be the change from winter vegetables to the richer, more varied and fresher choice of seasonal products in spring. In contrast to vegetables, a constant range of fruit is available throughout the year.

The present investigation shows that a majority of the respondents choose to consume fruit and vegetables because of the taste. As the health aspect plays a much smaller role in comparison, efforts to increase intake should increasingly consider the aspect of taste in addition to the health advantages. At the same time, the importance of availability should not be underestimated. Availability is regarded as a major reason for, as well as an important barrier to, consumption. Especially availability of fruit and vegetables at the place of work (also at canteens) plays an important role ${ }^{(43,44)}$.

In contrast to other studies, price was found to be only a minor barrier to consumption of fruit and vegetables. The importance of availability is affirmed by the fact that people often forget to eat fruit and vegetables, as well as naming preparation effort and inconvenience if not at home as barriers to consumption. Thus, it is advisable to improve availability in the future, while at the same time further emphasizing the ease of preparing and eating fruit and vegetables.

As most respondents stated that they consider their present intake sufficient, there is a question to what extent people are aware of daily requirements and whether there has been a lack of promoting an adequate desire for fruit and vegetables. Especially in this respect, the main objective should not be to draw attention to the well-known benefits of fruit and vegetables for human health $^{(45)}$, but to emphasize the taste aspect more.

To conclude, Austrian adults eat considerably too little fruit and vegetables. An increase in intake is possible if the existing potentials are utilized.

\section{Acknowledgements}

No funding was received for the present study. The authors have no conflicts of interest. M.S. was responsible for study design and data analysis, and contributed to the drafting of the paper. P.R. was responsible for study design and data discussion, and contributed to the drafting of the paper. I.E. was responsible for study design and proof reading of the paper.

\section{References}

1. World Health Organization (2003) Diet, Nutrition and the Prevention of Chronic Diseases. Joint WHO/FAO Expert Consultation. WHO Technical Report Series no. 916. Geneva: WHO.
2. Pomerleau J, Mc Kee M, Lobstein T \& Knai C (2003) The burden of disease attributable to nutrition in Europe. Public Health Nutr 6, 453-461.

3. Steinmetz K \& Potter JD (1996) Vegetables, fruit, and cancer prevention: a review. J Am Diet Assoc 96, 1027-1039.

4. Riboli E \& Norat T (2003) Epidemiologic evidence of the protective effect of fruit and vegetables on cancer risk. $\mathrm{AmJ}$ Clin Nutr 78, 559-569.

5. Gonzalez C, Navarro C, Martinez C et al. (2004) The European prospective investigation about cancer and nutrition (EPIC). Rev Esp Salud Publica 78, 167-176.

6. Word Cancer Research Fund/American Institute for Cancer Research (2007) Food, Nutrition, Physical Activity and the Prevention of Cancer: A Global Perspective. Washington, DC: AICR

7. Hung H-C, Joshipura KJ, Jiang R, Hu FB, Hunter D, SmithWarner SA, Colditz GA, Rosner B, Spiegelman D \& Willett WC (2004) Fruit and vegetable intake and risk of major chronic disease. J Natl Cancer Inst 96, 1577-1584.

8. Takachi R, Inoue M, Ishihara J, Kurahashi N, Iwasaki M, Sasazuki S, Iso H, Tsubono Y \& Tsugane S (2008) Fruit and vegetable intake and risk of total cancer and cardiovascular disease: Japan Public Health Center-Based Prospective Study. Am J Epidemiol 167, 59-70.

9. Dauchet L, Amouyel P, Hercberg S \& Dallongeville J (2006) Fruit and vegetable consumption and risk of coronary heart disease: a meta-analysis of cohort studies. J Nutr 136, $2588-2593$.

10. He FJ, Nowson CA, Lucas M \& MacGregor GA (2007) Increased consumption of fruit and vegetables is related to a reduced risk of coronary heart disease: meta-analysis of cohort studies. J Hum Hypertens 21, 717-728.

11. Dauchet L, Amouyel P \& Dallongeville J (2005) Fruit and vegetable consumption and risk of stroke: a meta-analysis of cohort studies. Neurology 65, 1193-1197.

12. He FJ, Nowson CA \& MacGragor GA (2006) Fruit and vegetable consumption and stroke: meta-analysis of cohort studies. Lancet 367, 320-326.

13. Hamer M \& Chida Y (2007) Intake of fruit, vegetables, and antioxidants and risk of type 2 diabetes: systematic review and meta-analysis. J Hypertens 25, 2361-2369.

14. Tohill BC (2005) Dietary Intake of Fruit and Vegetables and Management of Body Weight. Background Paper for the Joint FAO/WHO Workshop on Fruit and Vegetables for Health, 1-3 September 2004, Kobe, Japan. Atlanta, GA: Centers for Disease Control and Prevention.

15. Ashfield-Watt PAL (2006) Fruits and vegetables, 5+ a day: are we getting the message across? Asia Pac J Clin Nutr 15, 245-252.

16. Yeh M-C, Ickes SB, Lowenstein LM, Shuval K, Ammerman AS, Farris R \& Katz DL (2008) Understanding barriers and facilitators of fruit and vegetable consumption among a diverse multi-ethnic population in the USA. Health Promot Int 23, 42-51.

17. Kamphuis CBM, Giskes K, De Bruijn G-J, Wendel-Vos W, Brug J \& Van Lenthe FJ (2006) Environmental determinants of fruit and vegetable consumption among adults: a systematic review. Br J Nutr 96, 620-635.

18. John JH \& Ziebland S (2004) Reported barriers to eating more fruit and vegetables before and after participation in a randomized controlled trial: a qualitative study. Health Educ Res 19, 165-174.

19. Maclellan DL, Gottschall-Pass K \& Larsen R (2004) Fruit and vegetable consumption: benefits and barriers. Can J Diet Pract Res 65, 101-105.

20. Kromrey H (2006) Empirische Sozialforschung, 11th ed., pp. 262-265. Stuttgart: Lucius \& Lucius.

21. Beer-Borst S \& Amado R (1995) Validation of selfadministered 24-hour recall questionnaire used in a largescale dietary survey. Z Ernahrungswiss 34, 183-189. 
22. Dehne LI, Klemm C, Henseker G \& Hermann-Kunz E (1999) The German Food Code and Nutrient Data Base (BLS II.2). Eur J Epidemiol 15, 355-359.

23. Schofield WN (1985) Predicting basal metabolic rate, new standards and review of previous work. Hum Nutr Clin Nutr 39, 5-41.

24. Goldberg GR, Black AE, Jebb SA, Cole TJ, Murgatroyd PR, Coward WA \& Prentice AM (1991) Critical evaluation of energy intake data using fundamental principles of energy physiology: 1. Derivation of cut-off limits to identify underrecording. Eur J Clin Nutr 45, 569-581.

25. Black AE, Goldberg GR, Jebb SA, Livingstone MB, Cole TJ \& Prentice AM (1991) Critical evaluation of energy intake data using fundamental principles of energy physiology: 2 . Evaluating the results of published surveys. Eur J Clin Nutr 45, 583-599.

26. Black AE (2000) Critical evaluation of energy intake using the Goldberg cut-off for energy intake:basal metabolic rate. A practical guide to its calculation, use and limitations. Int J Obes Relat Metab Disord 24, 1119-1130.

27. Ferrari P, Slimani N, Ciampi A et al. (2002) Evaluation of under- and overreporting of energy intake in the 24-hour diet recalls in the European Prospective Investigation into Cancer and Nutrition (EPIC). Public Health Nutr 5, 1329-1345.

28. Elmadfa I, Freisling H, Koenig J et al. (2003) Obst und Gemüse. In Österreichischer Ernährungsbericht 2003, 1st ed., pp. 228-328 [I Elmadfa, editor]. Vienna: Department of Nutritional Sciences of the University of Vienna.

29. World Cancer Research Fund/American Institute for Cancer Research (2007) Food, Nutrition, Physical Activity, and the Prevention of Cancer: A Global Perspective, 1st ed., p. 28. Washington, DC: AICR.

30. Anderson AS \& Cox DN (2000) Five a day - challenges and achievements. Nutr Food Sci 30, 30-34.

31. Stewart H, Blisard N \& Jolliffe D (2003) Do income constraints inhibit spending on fruits and vegetables among low-income households? J Agric Resour Econ 28, 465-480.

32. Cassady D, Jetter KM \& Culp J (2007) Is price a barrier to eating more fruits and vegetables for low-income families? J Am Diet Assoc 107, 1909-1915.

33. Claro RM, Esvael do Carmo HC, Sarti Machado FM \& Monteiro CA (2007) Income, food prices, and participation of fruit and vegetables in the diet. Rev Saude Publica $\mathbf{4 1}$, 557-564.
34. Kiefer I, Rathmanner $\mathrm{T} \&$ \& Kunze M (2005) Eating and dieting differences in men and women. J Mens Health Gend 2, 194-201.

35. Kratt P, Reynolds K \& Shewchuk R (2000) The role of availability as a moderator of family fruit and vegetable consumption. Health Educ Behav 27, 471-482.

36. Cullen KW, Baranowski T, Owens E, Marsh T, Rittenberry L \& De Moor C (2003) Availability, accessibility, and preferences for fruit, $100 \%$ fruit juice, and vegetables influence children's dietary behaviour. Health Educ Behav 30, 615-626.

37. Jago R, Baranowski T \& Baranowski JC (2007) Fruit and vegetable availability: a micro environmental mediating variable? Public Health Nutr 10, 681-689.

38. Birner A, Fülöp G, Hlava A, Sax G \& Winkler P (2004) Gesundheit und Krankheit in Österreich - Österreichischer Gesundheitsbericht 2004, 1st ed., pp. 21-31. Vienna: Österreichisches Bundesinstitut für Gesundheitswesen.

39. Friel S, Newell J \& Kelleher C (2005) Who eats four or more servings of fruit and vegetables per day? Multivariate classification tree analysis of data from the 1998 Survey of Lifestyle, Attitudes and Nutrition in the Republic of Ireland. Public Health Nutr 8, 159-169.

40. Agudo A \& Pera G (1999) Vegetable and fruit consumption associated with anthropometric, dietary and lifestyle factors in Spain. Public Health Nutr 2, 263-271.

41. Pollard J, Greenwood D, Kirk S \& Cade J (2001) Lifestyle factors affecting fruit and vegetable consumption in the UK Women's Cohort Study. Appetite 37, 71-79.

42. Thompson RL, Margetts BM, Speller VM \& McVey D (1999) The Health Education Authority's health and lifestyle survey 1993: who are the low fruit and vegetable consumers? J Epidemiol Community Health 53, 294-299.

43. Anderson AS, Cox DN, McKellar S, Reynolds J, Lean ME \& Mela DJ (1998) Take Five, a nutrition education intervention to increase fruit and vegetable intakes: impact on attitudes towards dietary change. Br J Nutr 80, 133-140.

44. Oppen M, Sugarman S \& Foerster SB (2002) Fruit and vegetable consumption in California adults: ten-year highlights from the California Dietary Practices Surveys 1989-1999. http://www.phi.org/pdf-library/fruit_survey1102. pdf (accessed June 2008).

45. Blanck HM, Galuska DA, Gillespie C, Khan LK, Serdula MK, Solera MK, Mokdad AH \& Cohen LP (2007) Fruit and vegetable consumption among adults - United States in 2005. MMWR Morb Mortal Wkly Rep 56, 213-217. 